\title{
Multigene Panel Testing in a Large Cohort of Adults With Epilepsy
}

\section{Diagnostic Yield and Clinically Actionable Genetic Findings}

Dianalee McKnight, PhD, Sara L. Bristow, PhD, Rebecca M. Truty, PhD, Ana Morales, MS, Molly Stetler, MS, M. Jody Westbrook, PhD, Kristina Robinson, PhD, Darlene Riethmaier, MS, Felippe Borlot, MD, Marissa Kellogg, MD, Sean T. Hwang, MD, Anne Berg, PhD, and Swaroop Aradhya, PhD

Neurol Genet 2022;8:e650. doi:10.1212/NXG.0000000000000650

\section{Abstract}

\section{Background and Objectives}

Although genetic testing among children with epilepsy has demonstrated clinical utility and become a part of routine testing, studies in adults are limited. This study reports the diagnostic yield of genetic testing in adults with epilepsy.

\section{Methods}

Unrelated individuals aged 18 years and older who underwent diagnostic genetic testing for epilepsy using a comprehensive, next-generation sequencing-based, targeted gene panel (range 89-189 genes) were included in this cross-sectional study. Clinical information, provided at the discretion of the ordering clinician, was reviewed and analyzed. Diagnostic yield was calculated for all individuals including by age at seizure onset and comorbidities based on clinician-reported information. The proportion of individuals with clinically actionable genetic findings, including instances when a specific treatment would be indicated or contraindicated due to a diagnostic finding, was calculated.

\section{Results}

Among 2,008 individuals, a diagnostic finding was returned for 218 adults (10.9\%), with clinically actionable findings in $55.5 \%$ of diagnoses. The highest diagnostic yield was in adults with seizure onset during infancy $(29.6 \%, 0-1$ year), followed by in early childhood (13.6\%, 2-4 years), late childhood ( $7.0 \%, 5-10$ years), adolescence (2.4\%, $11-17$ years), and adulthood $(3.7 \%, \geq 18$ years). Comorbid intellectual disability (ID) or developmental delay resulted in a high diagnostic yield (16.0\%), most notably for females (19.6\% in females vs $12.3 \%$ in males). Among individuals with pharmacoresistant epilepsy, $13.5 \%$ had a diagnostic finding, and of these, $57.4 \%$ were clinically actionable genetic findings.

\section{Discussion}

These data reinforce the utility of genetic testing for adults with epilepsy, particularly for those with childhood-onset seizures, ID, and pharmacoresistance. This is an important consideration due to longer survival and the complexity of the transition from pediatric to adult care. In addition, more than half of diagnostic findings in this study were considered clinically actionable, suggesting that genetic testing could have a direct impact on clinical management and outcomes.
Correspondence

Dr. McKnight

dee.mcknight@invitae.com 


\section{Glossary}

$\mathbf{A R}=$ autosomal recessive; $\mathbf{A S D}=$ autism spectrum disorder $\mathbf{A S M}=$ antiseizure medication $\mathbf{C N V}=$ copy number variant $; \mathbf{D D}=$ developmental delay; ID = intellectual disability; NGS = next-generation sequencing.

Epilepsy, one of the most common neurologic conditions, is estimated to affect approximately 3.4 million individuals in the United States, of whom an estimated 3.0 million are adults. ${ }^{1}$ Genetic testing among children has demonstrated clinical utility and has increasingly become a part of routine clinical evaluation among pediatric neurologists, ${ }^{2,3}$ although there are limited guidelines for genetic testing for epilepsy. ${ }^{4}$ Early genetic testing has been shown to reduce time and costs associated with the diagnostic journey and may even be used to tailor clinical management (indicated or contraindicated therapies) to improve patient outcomes. ${ }^{6-9}$

For many adolescents and adults who developed epilepsy in childhood and before genetic testing was widely available and routine, the etiology of the disorder remains unknown as they transition from pediatric to adult care. In a recent study of a consecutive series of individuals undergoing genetic testing for epilepsy, only $10.7 \%$ of individuals were adults at the time of testing. ${ }^{8}$ A diagnostic yield of $22 \%-23 \%$ has been reported in 2 small studies of adults with epilepsy who mainly had intellectual disability (ID) or childhood-onset seizures. ${ }^{10,11}$ Both of these studies reported clinically actionable findings, that is, how clinical management changed due to a diagnostic result, demonstrating the clinical utility of such testing in adults. However, considering the small number of patients and potential narrow clinical focus from these previous studies, we aimed to investigate a larger and broader sample of adults with epilepsy who underwent clinical genetic investigation.

In this cross-sectional study, we report on the diagnostic yield of a multigene epilepsy genetic test in a consecutive cohort of over 2,000 adults. Clinical information was analyzed to identify subgroups that might have a particularly high diagnostic yield. Clinically actionable genetic findings were reported based on the published literature and expert opinion.

\section{Methods}

\section{Study Population}

Unrelated individuals aged 18 years and older who were referred for testing using the Invitae Epilepsy Panel from October 2015 through March 2020 were included. Ordering clinicians completed a test requisition form, prompting them to provide optional demographic and clinical information, including International Classification of Diseases, 10th Revision (ICD-10) diagnosis code(s), sex, self-reported race and/or ethnicity, age at seizure onset, family history, and free-text space to provide additional information (e.g., comorbidities, seizure type, and previous genetic testing). Of note, a small subset of the individuals included in this study (3.2\%) were reported on previously. ${ }^{10}$ In addition, molecular testing data from 1,049 of the adults (52.0\%) were also included in a larger study focused on childhood-onset epilepsy ${ }^{8}$; because the cohort in that study was composed mainly of children, the data from the adults were not reported in detail as we present here.

\section{Standard Protocol Approvals, Registrations, and Patient Consents}

In the present study, review and analysis of deidentified and aggregated data were approved for waiver of authorization by the Western Institutional Review Board (study number 1167406).

\section{Genetic Testing and Variant Interpretation}

Referring clinicians ordered epilepsy-related genes from a multigene panel that included anywhere from 89 to 133 genes depending on the time at testing, as genes were added to this panel over the course of the study period. Additional epilepsyrelated genes that were not included in the panel (at the time of testing) could also be ordered (range 1-64 genes), such as genes for glycine encephalopathy or genes that have preliminary evidence associations with epilepsy. The total number of epilepsyrelated genes that were ordered were included in this analysis (range 89-189 genes). Genes were targeted and sequenced via a short-read next-generation sequencing (NGS) assay that used genomic DNA extracted from blood or saliva samples as reported previously. ${ }^{8} \mathrm{~A}$ bioinformatics pipeline aligned sequencing reads and used community standard and custom algorithms that identified single nucleotide variants, small insertions or deletions (indels), large indels, structural variants, and exon-level copy number variants $(\mathrm{CNVs}){ }^{12,13}$ Clinically significant variants that did not meet stringent NGS quality metrics were confirmed by an orthogonal method before reporting. ${ }^{14}$

Variants identified by the bioinformatics pipeline were analyzed by Sherloc, ${ }^{15}$ a proprietary, points-based framework based on the joint consensus guidelines from the American College of Medical Genetics and Genomics and the Association for Molecular Pathology. Several pieces of evidence are considered when classifying a variant, including population data, the variant type, any clinical observations, experimental studies, and indirect and computational methods. Based on the synthesis of these data points, variants were classified as benign or likely benign $(\mathrm{B} / \mathrm{LB})$, variant(s) of uncertain significance (VUS), or pathogenic or likely pathogenic (P/LP). Once a variant is classified in 1 case, subsequent cases in which the variant is observed are automatically assigned the same interpretation in the absence of new data (i.e., new publications or internal inheritance/clinical information). Variants classified as P/LP or VUS were reported to clinicians, whereas $\mathrm{B} / \mathrm{LB}$ variants were not reported. 
A definitive molecular diagnosis was defined as either a single $\mathrm{P} / \mathrm{LP}$ variant in a gene associated with autosomal dominant or $\mathrm{X}$-linked inheritance or $2 \mathrm{P} / \mathrm{LP}$ variants (or a single homozygous variant) in genes associated with autosomal recessive (AR) inheritance. A VUS, a single $\mathrm{P} / \mathrm{LP}$ variant in an AR gene, and a heterozygous $\mathrm{P} / \mathrm{LP}$ variant and heterozygous VUS in the same AR gene were considered nondiagnostic findings. Negative findings occurred when no P/LP variants or VUS were reported.

\section{Analysis}

The proportions of individuals with a definitive molecular diagnosis (or diagnostic yield), a nondiagnostic finding (e.g., VUS and carrier), and a negative finding were calculated. Furthermore, for each gene, statistics regarding age at the time of testing (e.g., mean and median) were calculated for those with a diagnostic finding.

To understand potential associations between epilepsies with genetic etiologies and comorbidities, the age at onset, and pharmacoresistant seizures, information provided by ordering clinicians in free text fields on the test requisition form and ICD-10 codes (eTable 1, links.lww.com/NXG/A505) was extracted for review. The following information was focused on: age at onset, presence of ID or developmental delay (DD), autism spectrum disorder (ASD), pharmacoresistant seizures, and family history of neurologic disorders. As this information was provided at the discretion of the clinician, the amount of clinical detail varied, and the data were in a relatively unstructured manner. If a clinical feature was reported by the clinician, we assumed that feature was present in the individual; however, if a clinical feature was not noted, we considered the information missing rather than assuming that the individual did not have that feature. The diagnostic yield associated with each clinical feature was calculated based on the number of individuals with each clinical feature noted by the clinician on the test requisition form. Individuals with that clinical information missing were excluded from that analysis.

For age at seizure onset, some clinicians provided a specific age (e.g., age 5 or 1 month of age), whereas others used descriptive terminology (e.g., childhood, adolescence, or adulthood). Individuals were grouped by age at seizure onset in 2 ways. Some were grouped by a quantitative-based age range if a specific age at onset was noted (infant, $0-1$ year; early childhood, 2-4 years; late childhood, 5-10 years; adolescence, 11-17 years; and adult, 18 years or older). Diagnostic yields by these age groups were calculated. To accommodate a more complex analysis of investigating the impact of age at onset and other clinical features (e.g., ID/DD or family history), individuals with either a specific age or a descriptive age group were placed into 1 of 3 groups (childhood, $0-10$ years; adolescence, 11-17 years; and adult, 18 years or older).

Clinician-reported information and noted ICD-10 codes were searched to identify individuals with certain features. Individuals with noted ID, DD, or cognitive impairment were grouped as $\mathrm{ID} / \mathrm{DD}$. Individuals with ASD were also identified when autism or autism spectrum disorder was noted. Seizures were considered pharmacoresistant if the terms intractable or refractory were noted to describe the individual's seizures. Those with a family history of epilepsy, a neurologic disorder, and/or ID were also analyzed. In addition to calculating yield for individual characteristics, differences in diagnostic yield by demographic and clinical features were calculated by sex and age at seizure onset (including only those with this information provided).

For individuals with a diagnostic finding associated with autosomal dominant or X-linked inheritance who also had both parents subsequently tested, the frequency of detecting de novo variants (i.e., neither parent had the pathogenic variant found in their child and parentage was confirmed) was calculated. The proportion of individuals with a de novo variant was calculated. Among those with a diagnostic finding inherited from a parent, any clinical information provided was assessed to determine whether the individual had a personal history of epilepsy.

When appropriate, $\chi^{2}$ tests or Fisher exact tests were performed, with $p \leq 0.05$ considered statistically significant. To compare proportions among the different age groups, post hoc analysis determined the standardized residuals (z scores), with scores greater than 1.96 considered statistically significant $(p \leq 0.05)$.

Finally, a literature review identified specific clinical actions or changes in clinical management with reported positive outcomes for patients with pathogenic findings in certain genes. Molecular diagnoses in genes associated with disorders that had potential clinical implications were defined as epilepsyassociated genes in which a definitive molecular diagnosis could guide clinical management of the patient's seizures or underlying condition. A molecular diagnosis could be classified as clinically actionable if there was at least 1 published study demonstrating improved seizure control in a series of human participants; reports that included only animal studies or a single human participant were not sufficient. Although these treatments could be based on a molecular diagnosis, a number of these treatments are indicated for individuals diagnosed with seizures based solely on clinical presentation. These included genes that confer indications or contraindications for certain antiseizure medications (ASMs) for the daily maintenance of seizures, an inherited metabolic disorder with available treatments, or a potential indication or contraindication for surgery with high-resolution neuroimaging. In addition, genes with associated treatments related to other clinical presentations (e.g., other neurologic or cardiac-related symptoms) were also reviewed and considered clinically actionable, but were analyzed separately from clinically actionable implications for seizure management. ${ }^{16}$

\section{Data Availability}

The data that support the findings of this study are available from the corresponding author on reasonable request. 


\section{Results}

Requisition forms for 2,097 adults were reviewed for eligibility for this study. In total, 89 adults were excluded, including 80 adults who were relatives of probands who were previously tested and 9 who were a part of a $P C D H 19$-focused study with no demographic or clinical information available. Among the 2,008 unrelated adults included in this analysis, approximately half $(52.6 \%)$ were female, and the mean age at test requisition was $28.7 \pm 12.5$ years (range, 18-90 years) (Table 1). Selfreported races/ethnicities were Ashkenazi Jewish (1.8\%), Asian (4.4\%), Black (6.5\%), Hispanic (15.9\%), more than 1 race or ethnicity (3.4\%), other (4.4\%), unknown (9.0\%), Sephardic Jewish (0.7\%), and White (53.8\%). Age at epilepsy onset was reported in 839 (41.8\%) individuals, with adult onset the least common $(\mathrm{n}=173)$. At least 1 relevant clinical presentation (i.e., ID/DD, ASD, family history, or pharmacoresistant epilepsy) was noted for 1,381 (68.8\%) of the individuals (Table 1). Previous genetic testing was reported for 189 (9.4\%) individuals, most commonly chromosomal microarray $(\mathrm{n}=106)$, FMR1 CGG-repeat expansion testing $(\mathrm{n}=44)$, and karyotype $(\mathrm{n}=37)$. Most individuals had more than 150 epilepsy-related genes analyzed in our study (Table 1). Among the 839 referring clinicians from 567 centers, most self-identified as neurologists $(51.5 \%, \mathrm{n}=1,035)$, geneticists $(11.8 \%, \mathrm{n}=237)$, and pediatric or family medicine providers $(10.5 \%, \mathrm{n}=211)$.

\section{Diagnostic Yield}

A definitive molecular diagnosis was identified in 218 individuals (10.9\%) (Figure 1A). Diagnostic yield increased slightly, but not significantly, as the number of genes analyzed grew larger ( $<100$ genes, 9.1\%; 100-149 genes, $9.6 \%$; $\geq 150$ genes, $11.8 \%$; $\chi^{2}$ test for trend $\left.p=0.12\right)$. Diagnostic findings were detected in 61 genes (eTable 2, links.lww.com/NXG/ A505), with SCN1A $(\mathrm{n}=37)$ and MECP2 $(\mathrm{n}=14)$ representing the most common ones with a molecular diagnosis (Figure 1B). CNVs spanning multiple genes were observed in 4 individuals. Mean age at testing in individuals with a diagnostic finding was $27.7 \pm 10.2$ years (range, $18-78$ years) and varied by gene (Figure 1C). Nondiagnostic (e.g., VUS and carrier) and negative findings (e.g., no P/LP/VUS) were identified in $1,408(70.1 \%)$ and $382(19.0 \%)$ of the individuals, respectively.

When we assessed diagnostic yield according to clinicianprovided clinical and demographic, diagnostic yield was highest in adults with seizure onset during infancy $(29.6 \%)$ (Figure 2A). Generally, genes with diagnostic findings in individuals with adult-onset seizures were associated with reduced penetrance and variable expressivity (FLNA and LGI1), whereas those in individuals with earlier onset seizures were mostly associated with full penetrance and/or earlyonset syndromic diseases (e.g., SCN1A and PCDH19) (Figure 2B). Of comorbidities observed in addition to epilepsy, ID/DD resulted in the highest rate of definitive molecular diagnoses $(16.0 \%, \mathrm{n}=70 / 438$ ) (Figure 3A). A reported family history of neurologic issues was not correlated
Table 1 Demographic and Clinical Characteristics

\begin{tabular}{ll}
\hline Characteristic & $\begin{array}{l}\text { Study } \\
\text { population } \\
\mathbf{( N = 2 , 0 0 8 )}\end{array}$ \\
\hline Age at the time of testing, $\mathbf{y}$ & $28.7(12.5)$ \\
\hline Mean (SD) & $24(19,35)$ \\
\hline Median (Q1, Q3) & 18,90 \\
\hline Min, Max & $1,056(52.6)$ \\
\hline Sex, $\mathbf{n}$ (\%) & $952(47.4)$ \\
\hline Female & \\
\hline Male & $450(22.4)$ \\
\hline Onset, $\mathbf{n}$ (\%) & $216(10.8)$ \\
\hline Childhood & $173(8.6)$ \\
\hline Adolescent & $1,169(58.2)$ \\
\hline Adulthood & $1,570(78.2)$ \\
\hline Not disclosed & $438(21.8)$ \\
\hline ID/DD, $\mathbf{n}$ (\%) & \\
\hline Reported & $19.7)$ \\
\hline Not disclosed & \\
\hline ASD, $\mathbf{n}$ (\%) & \\
\hline Reported & \\
\hline Not disclosed & \\
\hline
\end{tabular}

Pharmacoresistant seizures, n (\%)

\begin{tabular}{ll}
\hline Reported & $798(39.7)$ \\
\hline Not disclosed & $1,210(60.3)$ \\
\hline
\end{tabular}

Positive family history of neurologic disorders, $\mathrm{n}(\%)$

\begin{tabular}{ll}
\hline Reported & $598(29.8)$ \\
\hline Not disclosed & $1,410(70.2)$ \\
\hline Previous genetic testing $^{\text {a }}$ & $189(9.4)$ \\
\hline Reported & $1,819(90.6)$ \\
\hline Not disclosed & \\
\hline Number of genes analyzed & $33(1.6)$ \\
\hline$<\mathbf{1 0 0}$ & $841(41.9)$ \\
\hline $\mathbf{1 0 0}-149$ & $1134(56.5)$ \\
\hline$\geq \mathbf{1 5 0}$ &
\end{tabular}

Abbreviations: $\mathrm{ASD}=$ autism spectrum disorder; $\mathrm{DD}=$ developmental delay; $\mathrm{ID}=$ intellectual disability; $\mathrm{Q}=$ quintile; $\mathrm{SD}=$ standard deviation.

${ }^{a}$ Includes FISH (fluorescence in situ hybridization), targeted variant testing, other indication panel, and not specified).

with a higher diagnostic yield (8.5\%). Finally, 189 individuals had other types of previous genetic testing (Table 1), and 33 (17.4\%) of them had a molecular diagnosis by panel testing in this study. 


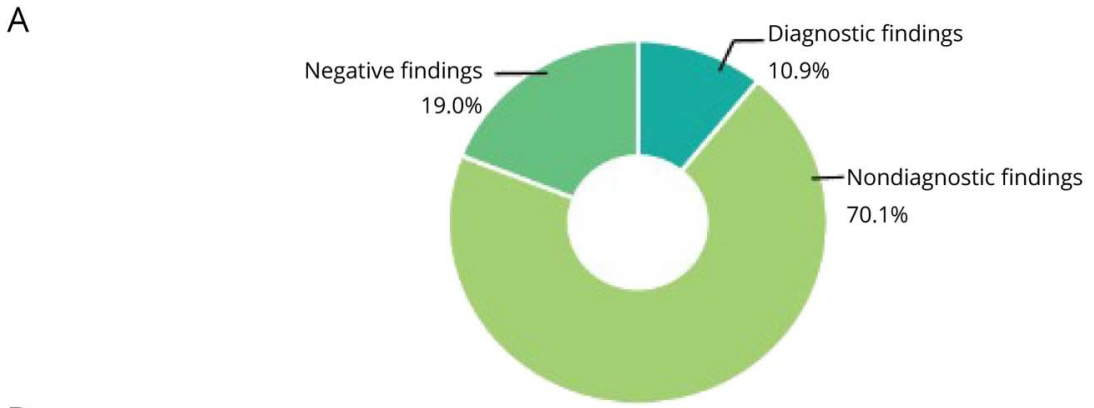

$\mathrm{B}$

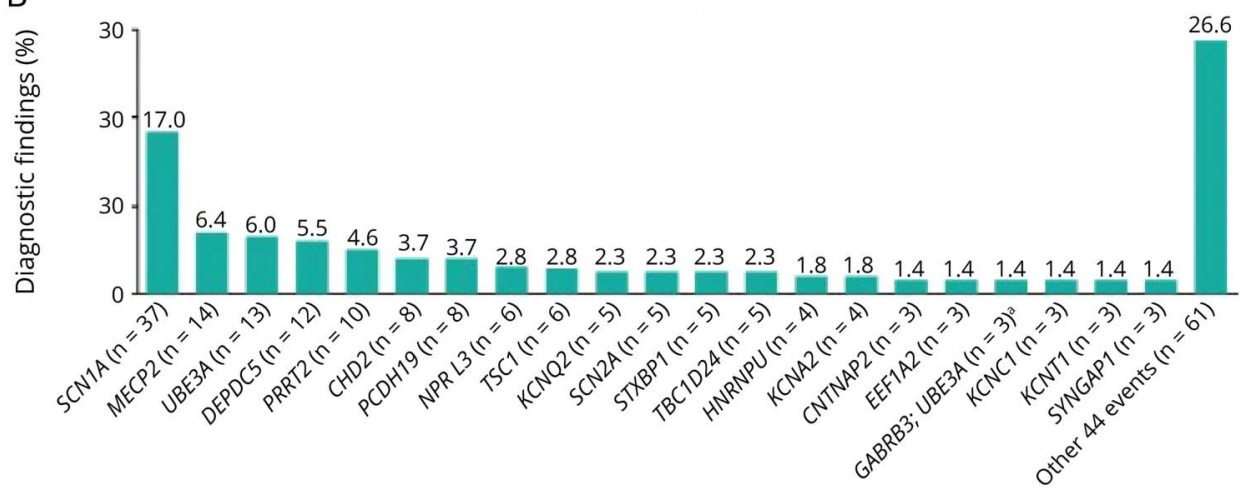

C

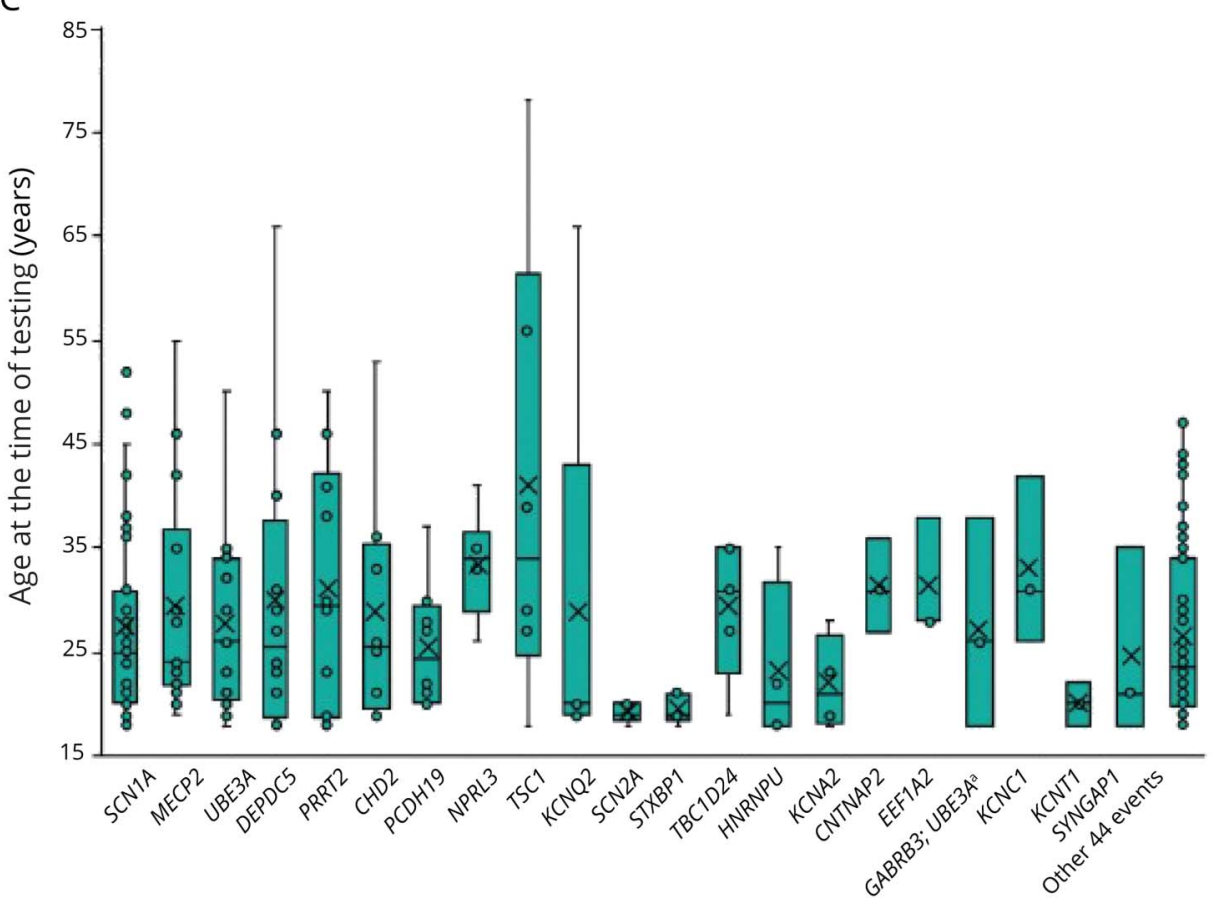

(A) Individuals in the study population were categorized according to their genetic test results. A definitive molecular diagnosis was defined as 1 pathogenic/ likely pathogenic $(P / L P)$ variant in a gene with autosomal dominant or X-linked inheritance or 2 P/LP variants (or a single homozygous variant) in a gene with autosomal recessive (AR) inheritance. $A$ nondiagnostic finding was any combination of reported variant(s) that did not meet the definition of a definitive molecular diagnosis; this included variant(s) of uncertain significance (VUS), a single $P / L P$ variant in an AR gene, and a heterozygous P/LP variant and heterozygous VUS in the same AR gene. A negative finding occurred when no variants were reported, although benign or likely benign variants may have been detected. (B) Among those with a diagnostic finding, frequency was calculated by gene. The number of individuals with a diagnostic finding in a gene is indicated in parentheses along the $x$-axis. Each of the genes in the Other 44 events group individually accounted for $<1 \%$ of the total diagnostic findings. A full summary of the genes with diagnostic findings can be found in eTable 2 (links.lww.com/NXG/ A505). (C) Among those with a diagnostic finding, a box and whisker plot reporting age at the time of testing was constructed. Line indicates the inclusive median; Xindicates the average; bottom of box indicates the first quartile; top of box indicates the third quartile; whiskers indicate the minimum and maximum ages; dots indicate outliers. ${ }^{\mathrm{a}} \mathrm{A}$ pathogenic copy number variant spanning both genes was observed as a single event.
Diagnostic yield varied by sex and age, as well as by the presence of ID/DD. Although the overall diagnostic yield was similar among female and male individuals $(11.6 \%$ vs $10.1 \%$, respectively; $p=0.230$ ), female individuals with ID/DD had a definitive molecular diagnosis more often than male individuals with ID/DD ( $19.6 \%$ vs $12.3 \%$; $p=0.037)$ (Figure 3B). This was in large part due to disease-causing variants in $M E C P 2$ and PCDH19. Furthermore, the diagnostic yield in individuals with childhood-onset seizures remained higher $(p<0.0001)$ than that for individuals with adolescent- and adult-onset seizures, both overall and regardless of sex or family history (Figure 3C). ID/DD appeared to be associated with similar diagnostic yields in individuals with childhoodand adult-onset seizures, both of whom had a higher diagnostic yield than those with adolescent-onset seizures. However, it is important to note that the sample of individuals 


\section{A}

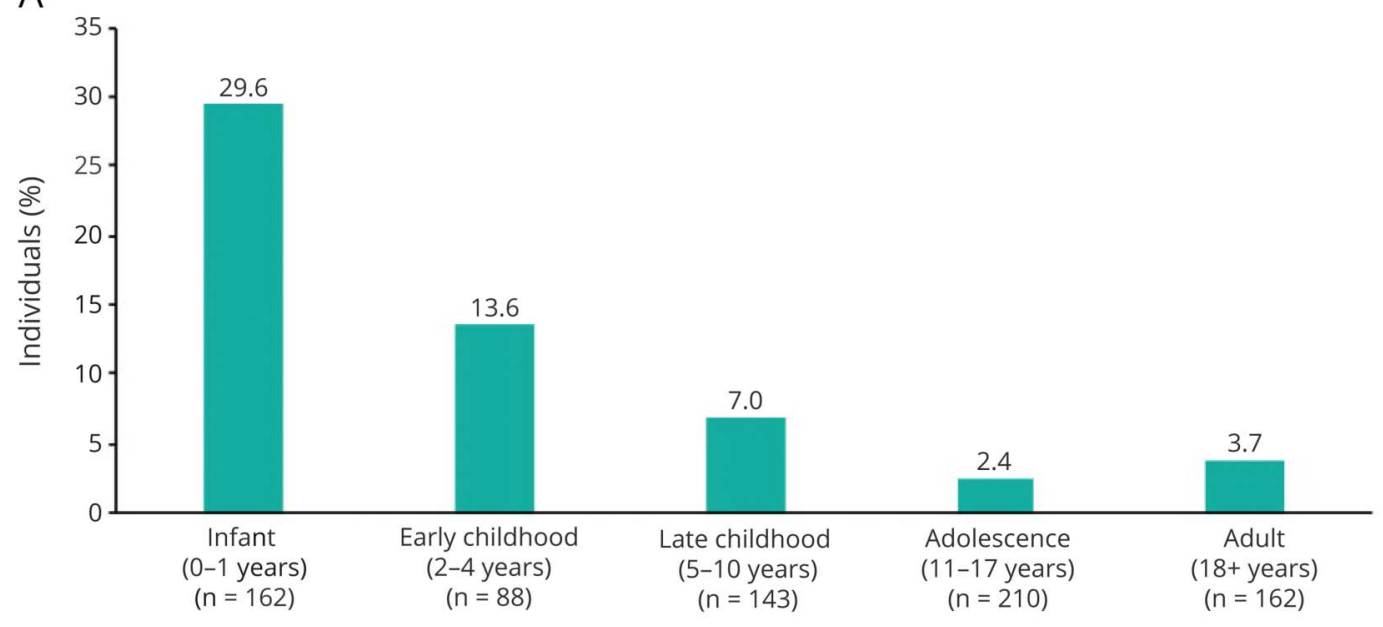

Age of seizure onset

B

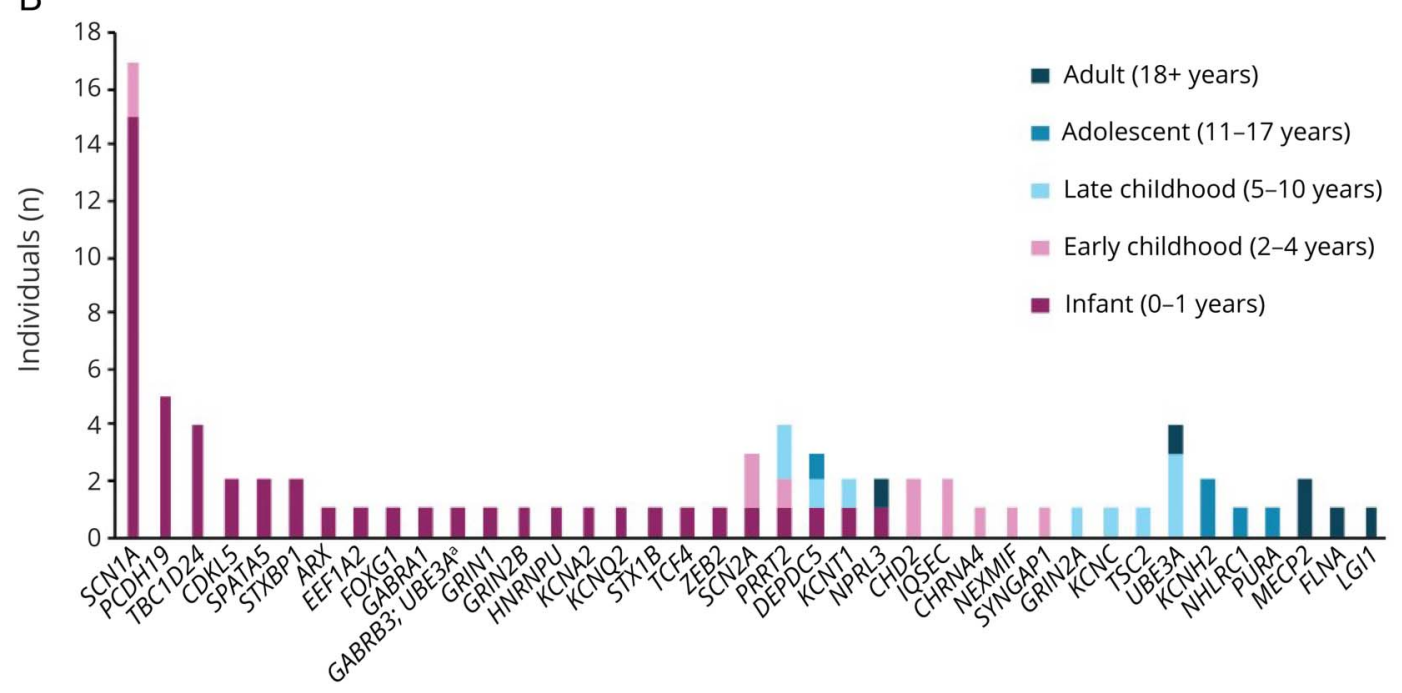

(A) The proportion of individuals with a definitive molecular diagnosis was calculated based on age at seizure onset (age groups defined in x-axis). (B) Among those with a definitive molecular diagnosis, the number of individuals with diagnostic findings in each gene was stratified according to age at seizure onset (age groups defined in the legend). These analyses included only individuals with a noted numerical age at onset. ${ }^{\mathrm{a}} \mathrm{A}$ pathogenic copy number variant spanning both genes was observed as a single event.

with adolescent- and adult-onset seizures with ID/DD was small; consequently, these findings should only be considered preliminary evidence.

\section{Inheritance Trends}

To understand the inheritance patterns of the P/LP variants in adults with genetic epilepsy, individuals with a definitive molecular diagnosis in genes with autosomal dominant or $\mathrm{X}$-linked inheritance who also had both parents tested were analyzed. In total, 30 individuals met these criteria. The diagnostic finding was de novo in $83.3 \%(n=25)$ of cases. Among the 5 remaining inherited cases, variants identified in 2 parents were consistent with unaffected status due to their unique modes of inheritance (father positive for PCDH19 variant and mother positive for $U B E 3 A$ variant), 1 parent was reported to be unaffected (DEPDC5, known to have reduced penetrance), 1 was reported to be affected (ATP1A2), and 1 had no information reported about the parent (PRRT2).

\section{Clinically Actionable Findings}

Of the 218 individuals with a definitive molecular diagnosis, 121 (55.5\%) had diagnostic findings in 1 of 22 genes associated with specific treatment for seizure control (eTable3, links.lww.com/ NXG/A505). The most common genes with a clinically actionable finding were SCN1A, DEPDC5, PRRT2, PCDH19, and TSC1. Diagnostic findings in genes with ASM indications were the most common category of clinically actionable findings $(\mathrm{n}=$ 99), followed by those in genes with possible surgical interventions $(n=64)$ (Figure 4A). Two of the 8 individuals with adultonset seizures and a molecular diagnosis had clinically actionable findings ( $L G I 1$ and NPRL3). In addition, 9 individuals had diagnostic findings in 4 genes ( $A T P 1 A 3, C A C N A 1 A, K C N H 2$, and 

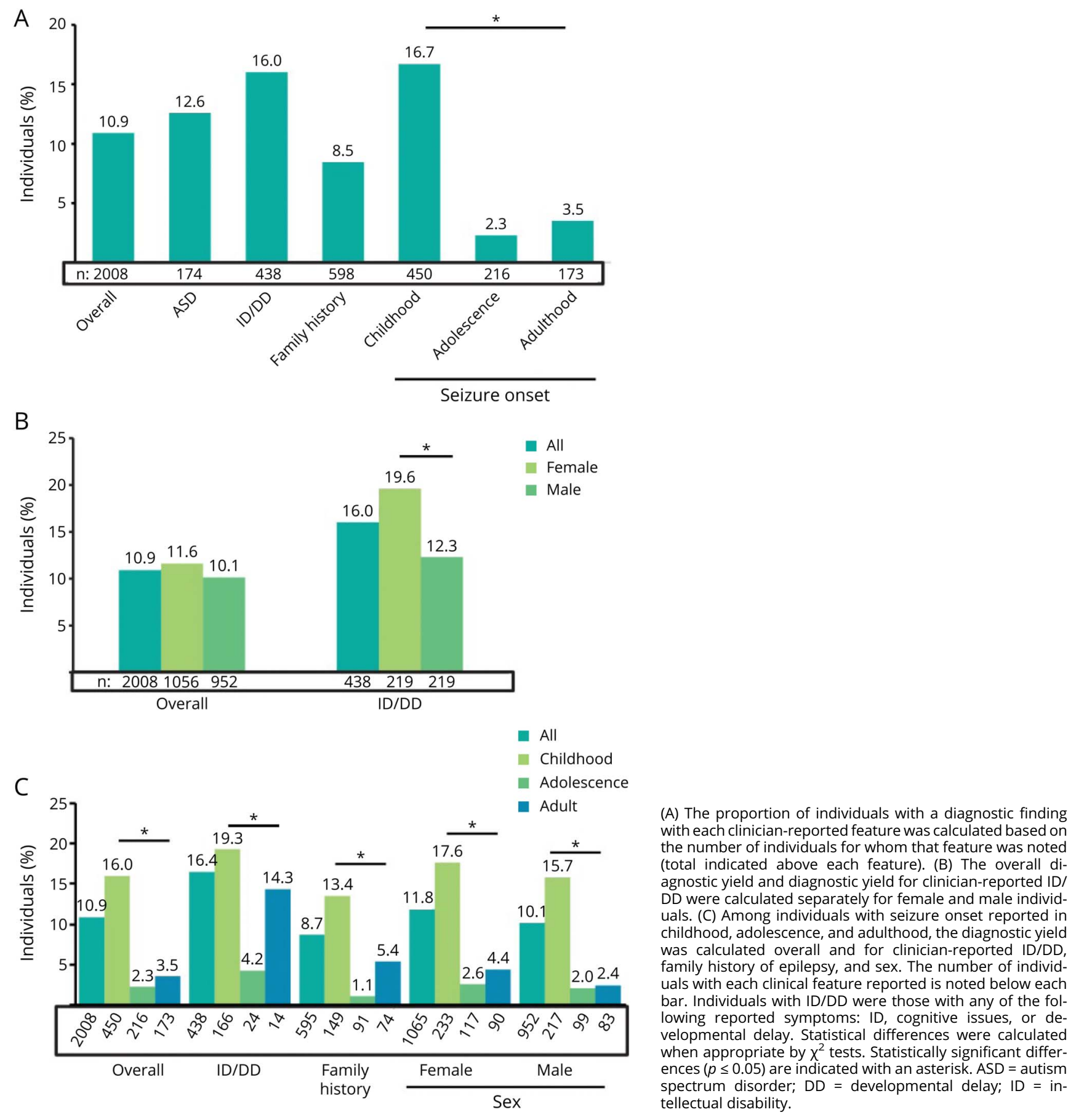

STXBP1) associated with clinical management implications that would affect other aspects of their care (eTable 3, links.lww. com/NXG/A505).

Among the 108 of 798 (13.5\%) individuals with pharmacoresistant epilepsy who received a molecular diagnosis, more than half $(62,57.4 \%)$ had clinically actionable diagnostic findings. These were evenly split between ASM indications, ASM contraindications, metabolic treatment, possible surgical indications, and surgical contraindications (Figure 4B).

\section{Discussion}

The genetic etiology of epilepsy is heterogeneous, and multigene epilepsy genetic testing is an efficient, accurate, and cost-effective test used by clinicians in the diagnostic, therapeutic, and prognostic journey. The majority of individuals with epilepsy in the United States are adults (whose epilepsy often began in childhood), ${ }^{1,17,18}$ but genetic testing is not routinely used by their treating clinicians. With the recent advances in testing methods, some of these adults may not 

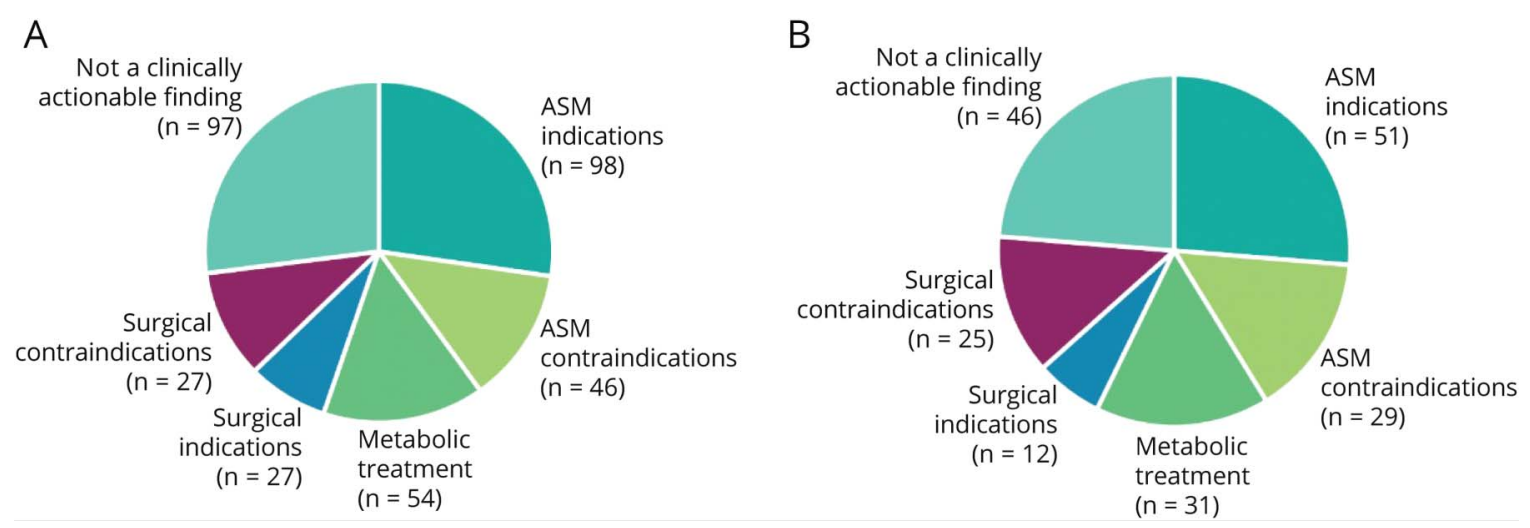

(A) All definitive molecular diagnoses and (B) definitive molecular diagnoses with pharmacoresistant seizures were categorized according to whether the diagnostic finding was in a gene with a published clinical action and if so, the type (ASM indications, ASM contraindications, metabolic treatments, possible surgical indications, or surgical contraindications). Individuals with clinically actionable findings in more than 1 category were counted more than once. A full list of clinically actionable genetic findings can be found in eTable 3 (links.lww.com/NXG/A505). ASM = antiseizure medication.

have had genetic testing available to them, whereas others may have had testing performed but on a limited set of genes. Adult neurologists have reported discomfort with diagnosing and treating patients with childhood-onset genetic syndromes, ${ }^{19}$ although it has been estimated that up to $75 \%$ of individuals with childhood-onset epilepsy due to genetic causes will require ongoing care into adulthood. ${ }^{20,21}$ These observations demonstrate that neurologists should be aware of undiagnosed genetic disorders in their adult patients who have transitioned from pediatric care. The transition period is an ideal time to rethink the individual's diagnosis, to consider repeating genetic testing, and to optimize disease management. ${ }^{22}$ In this cohort, nearly one-fifth of individuals who had previous genetic testing reported received a molecular diagnosis through testing on a multigene panel, including those who had testing following a chromosomal microarray result. This study describes some of the oldest individuals with genetic epilepsy, some of whom were aged between 50 and 70 years, demonstrating that individuals with certain types of genetic epilepsy can live well into adulthood. Without broader testing of adults with active seizures or with a history of resolved childhood seizures, the complete natural history of many of these genetic epilepsy disorders will remain elusive. The results presented here support calls for expanding testing to adults with epilepsy, ${ }^{10,11,23}$ especially those with medically refractory epilepsy of childhood onset or with comorbid ID.

Importantly, the diagnostic yield was similar regardless of the number of epilepsy-related genes analyzed. Although there was a small increase in yield as the panel size grew, these findings are consistent with other studies reporting that the majority of molecular diagnoses are in a smaller subset of genes that are tested. ${ }^{8,24}$ As expected, the diagnostic yield was much higher in a population enriched for ID/DD compared with the overall unselected study population $(16.0 \%$ vs $10.9 \%)$. Furthermore, this higher rate is similar to previous studies assessing the diagnostic yield in adults with a suspected genetic etiology for their childhood-onset epilepsy and ID/DD (22\%-23\%). ${ }^{10,11}$ Importantly, patients were excluded from the cohorts if acquired epilepsies were identified (e.g., hypoxic-ischemic injury, stroke, and metastatic brain disease) as these individuals are expected to not benefit from genetic testing. However, it is important to note that motor symptoms developed by some patients with genetically determined epilepsies can mislead clinicians to a diagnosis of an acquired chronic nonprogressive encephalopathy (i.e., cerebral palsy). For example, tetraparesis with spasticity is not rare in adults harboring KCNQ2 pathogenic variants, ${ }^{24}$ whereas COL4A1 variants may lead to hemiplegia and porencephaly. ${ }^{25,26}$ Moreover, patients with GLUT-1 deficiency may present with gait disturbances that could resemble dyskinetic or ataxic cerebral palsy. ${ }^{27-30}$ Thus, only a suspicion of an acquired symptomatic seizure disorder might not be sufficient to rule out the possibility of a genetic etiology.

We also demonstrate that the diagnostic yield is similar among individuals with ID/DD regardless of age at seizure onset. We also observed a significantly higher diagnostic yield in female individuals with ID/DD than male individuals with ID/DD, mainly due to diagnostic findings in X-linked genes historically known to affect female individuals at a greater rate than male individuals (i.e., MECP2 and PCDH19), but possibly also due to elevated mortality of male fetuses with pathogenic variants in these genes in utero. Of note, this study did not test FMR1 repeat expansions for Fragile X syndrome, which is one of the most common causes of ASD/ID in males, with seizures reported as a common comorbidity. ${ }^{31,32}$ Furthermore, we found that a noted family history was not associated with a higher diagnostic yield and that the majority of individuals (83.3\%) with parental results available had de novo pathogenic variants. These findings are consistent with previous literature that reported on the diagnostic yield in the 
absence of a positive family history of epilepsy and the overall high de novo rates for many of these genes. ${ }^{2433}$ These data suggest that individuals with epilepsy of unexplained cause presenting at any age and with ID/DD comorbidities, regardless of family history, often have an identifiable genetic diagnosis.

We have demonstrated that a molecular diagnosis may help guide clinical management decisions at the discretion of the treating clinician, as evidenced by over half of the individuals in this study having potentially clinically actionable diagnostic findings. The proportion of individuals with clinically actionable implications is only expected to grow as new precision medicine therapies continue to become available. Occasionally, a diagnostic finding had clinical management implications beyond epilepsy care ( $4.1 \%$ of patients with a diagnostic finding). For example, a young adult in our cohort with medically refractory seizure-like activity was found to have a pathogenic variant in the $\mathrm{KCNH} 2$ gene, which is associated with long QT syndrome and sudden cardiac death ${ }^{34}$; therefore, an evaluation by cardiology was recommended. Similarly, we identified individuals with a molecular diagnosis in ATP1A3, CACNA1A, and STXBP1 that have clinical implications for treating movement disorders and/or migraines. Gene-specific treatment changes led to an improvement in the patient's seizure burden and overall well-being in $17 \%$ of positive cases. ${ }^{11} \mathrm{Al}$ though clinical management changes because of genetic testing results were not provided for our study, these data together support the value of genetic testing in adults, with findings possibly having a significant impact on overall health and even reducing health care costs. Future research should specifically evaluate how genetic testing results affect clinical management and patient care.

This study reported on the diagnostic yield among individuals who received a multigene NGS test for epilepsy. In addition to reporting molecular diagnoses, clinical genetic testing reports include VUS. Clinicians should take caution in interpreting a VUS as causative. A patient with a VUS in a gene associated with a disorder that is consistent with a patient's clinical presentation may later have the result reclassified as $\mathrm{P} / \mathrm{LP}$ with additional information (e.g., family testing, new clinical symptoms, and other patient observations) not available at the time of the original classification. However, a recent study demonstrated that the majority of VUS in individuals with epilepsy were downgraded to benign or likely benign. ${ }^{35}$ Furthermore, a negative result (i.e., no P/LP findings or VUS) does not preclude a genetic etiology of epilepsy. Although NGS panels can in general detect a wide range of genetic abnormalities, other assays may be able to detect a different set of genetic abnormalities, including chromosomal microarray, whole-exome or whole-genome sequencing, karyotype, or mitochondrial DNA sequencing. Limited studies in adults have demonstrated the use of such testing methods. ${ }^{36-38}$ Selecting the appropriate genetic test will depend on the patient's clinical presentation, prior genetic testing results, and family history. ${ }^{36,37,39}$
The data reported here were limited by variability in clinicianreported medical histories and clinical presentations. At least some additional clinician-provided information was available for $78.1 \%$ of individuals, but was not uniform or complete as this was optional to provide. It is unknown how many individuals in this study had comorbidities that were not reported to us by the clinician. Although clinical information can provide additional criterion for variant interpretation and should always be provided, it is not a prerequisite for determining pathogenicity. ${ }^{5}$

The data presented here highlight the need to increase awareness of and access to genetic testing for epilepsy among adults, regardless of the age at seizure onset. As our understanding of the genetic causes of epilepsy expands, the use of a multigene panel, exome sequencing, and/or whole genome sequencing, as well as the increasing availability of precision medicine (including gene-targeted therapies), will continue to expand, resulting in increased clinically actionable gene findings. It is critical to increase awareness of genetic testing among neurologists and epileptologists treating adults with epilepsy so that testing will become more routine. It is especially important for neurologists to be aware of undiagnosed genetic disorders in their adult patients who graduated from pediatric care.

\section{Acknowledgment}

The authors thank Kerry Aradhya and Sarah Poll, PhD, of Invitae for copyediting and data analysis support, respectively.

\section{Study Funding}

No targeted funding reported.

\section{Disclosures}

DM, SLB, RT, AM, MJW, KR, DR, MS, and SA are employed by and shareholders in Invitae. FB, MK, and STH report no disclosures. ATB has grant funding from the Pediatric Epilepsy Research Foundation, the FamilieSCN2A Foundation, the Dravet Syndrome Foundation, and the NINDS. Go to Neurology.org/NG for full disclosure.

\section{Publication History}

Received by Neurology: Genetics July 15, 2021. Accepted in final form November 4, 2021.

Appendix Authors

\begin{tabular}{lll}
\hline Name & Location & Contribution \\
\hline $\begin{array}{l}\text { Dianalee } \\
\text { McKnight, }\end{array}$ & Invitae, San Francisco, CA & Drafting/revision of the \\
PhD & & manuscript for content, \\
& including medical writing for \\
& content; major role in the \\
& acquisition of data; study \\
& concept or design; and analysis \\
& or interpretation of data
\end{tabular}


Appendix (continued)

\begin{tabular}{lll}
\hline Name & Location & Contribution \\
\hline $\begin{array}{l}\text { Sara L } \\
\text { Bristow, }\end{array}$ & Invitae, San Francisco, CA & $\begin{array}{l}\text { Drafting/revision of the } \\
\text { manuscript for content, } \\
\text { PhD }\end{array}$ \\
& $\begin{array}{l}\text { including medical writing for } \\
\text { content; study concept or } \\
\text { design; and analysis or } \\
\text { interpretation of data }\end{array}$ \\
\end{tabular}

Rebecca M. Invitae, San Francisco, CA Truty, PhD
Appendix (continued)

\begin{tabular}{lll}
\hline Name & Location & Contribution \\
\hline $\begin{array}{ll}\text { Swaroop } \\
\text { Aradhya, }\end{array}$ & Invitae, San Francisco, CA & $\begin{array}{l}\text { Drafting/revision of the } \\
\text { manuscript for content, } \\
\text { PhD }\end{array}$ \\
& $\begin{array}{l}\text { including medical writing for } \\
\text { content; study concept or } \\
\text { design; and analysis or } \\
\text { interpretation of data }\end{array}$ \\
\end{tabular}

\section{References}

1. Zack MM, Kobau R. National and State estimates of the numbers of adults and children with active epilepsy-United States, 2015. MMWR Morb Mortal Wkly Rep. 2017;66(31):821-825.

2. Berg AT, Coryell J, Saneto RP, et al Early-life epilepsies and the emerging role of genetic testing. JAMA Pediatr. 2017;171(9):863-871.

3. Shellhaas RA, Wusthoff CJ, Tsuchida TN, et al Profile of neonatal epilepsies: characteristics of a prospective US cohort. Neurology. 2017;89(9):893-899.

4. Jain P, Andrade D, Donner E, et al Development of criteria for epilepsy genetic testing in Ontario, Canada. Can J Neurol Sci. 2019;46(1):7-13

5. Richards S, Aziz N, Bale S, et al Standards and guidelines for the interpretation of sequence variants: a joint consensus recommendation of the American College of medical genetics and genomics and the Association for molecular pathology. Genet Med. 2015;17(5):405-424. $\begin{array}{lll}\text { Molly } & \text { Invitae, San Francisco, CA } & \begin{array}{l}\text { Drafting/revision of the } \\ \text { manuscript for content, }\end{array}\end{array}$ including medical writing for content; major role in the acquisition of data; and analysis or interpretation of data

M. Jody Invitae, San Francisco, CA
Westbrook,
PhD

Drafting/revision of the manuscript for content, including medical writing for content, and analysis or interpretation of data

\begin{tabular}{lll}
\hline $\begin{array}{l}\text { Kristina } \\
\text { Robinson, } \\
\text { PhD }\end{array}$ & Invitae, San Francisco, CA & $\begin{array}{l}\text { Drafting/revision of the } \\
\text { manuscript for content, } \\
\text { including medical writing for } \\
\text { content, and analysis or } \\
\text { interpretation of data }\end{array}$ \\
\hline $\begin{array}{l}\text { Darlene } \\
\text { Riethmaier, } \\
\text { MS }\end{array}$ & Invitae, San Francisco, CA & $\begin{array}{l}\text { Drafting/revision of the } \\
\text { manuscript for content, } \\
\text { including medical writing for } \\
\text { content, and analysis or } \\
\text { interpretation of data }\end{array}$ \\
\end{tabular}

Felippe Alberta Children's Hospital Drafting/revision of the

Borlot, MD Research Institute, Cumming manuscript for content, School of Medicine, including medical University of Calgary, Canada writing for content, and analysis or interpretation of data

$\begin{array}{ll}\text { Marissa } & \text { Oregon Health \& Science } \\ \text { Kellogg, MD } & \begin{array}{l}\text { University Comprehensive } \\ \text { Epilepsy Center }\end{array}\end{array}$

Drafting/revision of the manuscript for content, including medical writing for content, and analysis or interpretation of data

\begin{tabular}{ll}
\hline Sean T. & Department of Neurology, \\
Hwang, MD & Donald and Barbara Zucker \\
& School of Medicine at
\end{tabular}
Hofstra/Northwell

\section{Drafting/revision} of the manuscript for content, including medical writing for content, and analysis or interpretation of data

\begin{tabular}{lll}
\hline Anne Berg, & Epilepsy Center, Ann \& & Drafting/revision of the \\
PhD & Robert H. Lurie Children's & manuscript for content, \\
& Hospital of Chicago, & including medical writing for \\
Chicago, IL; Department & content, and analysis or \\
& of Neurology, Northwestern & interpretation of data \\
University-Feinberg School & \\
& of Medicine, Chicago, IL &
\end{tabular}

6. Oates $\mathrm{S}$, Tang $\mathrm{S}$, Rosch $\mathrm{R}$, et al. Incorporating epilepsy genetics into clinical practice: $360^{\circ}$ evaluation. NPJ Genom Med. 2018;3:13.

7. Myers KA, Johnstone DL, Dyment DA. Epilepsy genetics: current knowledge, applications, and future directions. Clin Genet. 2019;95(1):95-111.

8. Truty R, Patil N, Sankar R, et al Possible precision medicine implications from genetic testing using combined detection of sequence and intragenic copy number variants in a large cohort with childhood epilepsy. Epilepsia Open. 2019;4(3):397-408.

9. Hoelz H, Herdl C, Gerstl L, et al Impact on clinical decision making of nextgeneration sequencing in pediatric epilepsy in a tertiary epilepsy referral center. Clin EEG Neurosci. 2020;51(1):61-69.

10. Borlot F, de Almeida BI, Combe SL, Andrade DM, Filloux FM, Myers KA. Clinica utility of multigene panel testing in adults with epilepsy and intellectual disability. Epilepsia. 2019;60(8):1661-1669.

11. Johannesen KM, Nikanorova N, Marjanovic D, et al Utility of genetic testing for therapeutic decision-making in adults with epilepsy. Epilepsia. 2020;61(6):1234-1239.

12. Lincoln SE, Kobayashi $Y$, Anderson MJ, et al A systematic comparison of traditional and multigene panel testing for hereditary breast and ovarian cancer genes in more than 1000 patients. J Mol Diagn. 2015;17(5):533-544.

13. Truty R, Paul J, Kennemer M, et al Prevalence and properties of intragenic copynumber variation in Mendelian disease genes. Genet Med. 2019;21(1):114-123.

14. Lincoln SE, Truty R, Lin CF, et al A rigorous interlaboratory examination of the need to confirm next-generation sequencing-detected variants with an orthogonal method in clinical genetic testing. J Mol Diagn. 2019;21(2):318-329.

15. Nykamp K, Anderson M, Powers M, et al Sherloc: a comprehensive refinement of the ACMG-AMP variant classification criteria. Genet Med. 2017;19(10):1105-1117.

16. Devinsky O, Hesdorffer DC, Thurman DJ, Lhatoo S, Richerson G. Sudden unexpected death in epilepsy: epidemiology, mechanisms, and prevention. Lancet Neurol. 2016;15(10):1075-1088.

17. Berg AT. Understanding the delay before epilepsy surgery: who develops intractable focal epilepsy and when? CNS Spectr. 2004;9(2):136-144.

18. Chipaux M, Szurhaj W, Vercueil L, et al Epilepsy diagnostic and treatment needs identified with a collaborative database involving tertiary centers in France. Epilepsia. 2016;57(5):757-769.

19. Borlot F, Tellez-Zenteno JF, Allen A, Ali A, Snead OC 3rd, Andrade DM. Epilepsy transition: challenges of caring for adults with childhood-onset seizures. Epilepsia.

20. Lewis-Smith D, Ellis CA, Helbig I, Thomas RH. Early-onset genetic epilepsies reaching adult clinics. Brain 2020;143(3). p. e19.

21. Lewis-Smith D, Thomas RH. The prevalence of genetically diagnosable epilepsies in young adulthood: how many should we be looking for Epilepsia. Epub August 12, 2020. dx.doi.org/10.1111/epi.16640.

22. Andrade DM, Bassett AS, Bercovici E, et al Epilepsy: transition from pediatric to adult care. Recommendations of the Ontario epilepsy implementation task force. Epilepsia. 2017;58(9):1502-1517

23. Ottman R, Poduri A. Gene tests in adults with epilepsy and intellectual disability. Nat Rev Neurol. 2020;16(10):527-528.

24. Lindy AS, Stosser MB, Butler E, et al Diagnostic outcomes for genetic testing of 70 genes in 8565 patients with epilepsy and neurodevelopmental disorders. Epilepsia. 2018;59(5):1062-1071.

25. Boets S, Johannesen KM, Destree A, et al. Adult phenotype of KCNQ2 encephalopathy. J Med Genet. Epub April 2, 2021. dx.doi.org/10.1136/jmedgenet-2020107449.

26. Plaisier E, Ronco P. COL4A1-Related disorders. In: Adam MP, Ardinger HH, Pagon RA, et al., eds. GeneReviews ${ }^{\circledast}$. University of Washington, Seattle; 2009. 2014;55(10):1659-1666. 
27. Bi D, Wang H, Shang $\mathrm{Q}$ et al Association of COL4Al gene polymorphisms with cerebral palsy in a Chinese Han population. Clin Genet. 2016;90(2):149-155.

28. Wang D, Pascual JM, De Vivo D. Glucose transporter type 1 deficiency Syndrome. In: Adam MP, Ardinger HH, Pagon RA, et al., eds. GeneReviews ${ }^{\circledR}$. University of Washington, Seattle; 2002.

29. Pons R, Collins A, Rotstein M, Engelstad K, De Vivo DC. The spectrum of movement disorders in Glut-1 deficiency. Mov Disord. 2010;25(3):275-281.

30. Kim H, Lee JS, Lee Y, et al Diagnostic challenges Associated with GLUT1 deficiency: phenotypic variabilities and evolving clinical features. Yonsei Med J. 2019;60(12): 1209-1215.

31. Hunter JE, Berry-Kravis E, Hipp H, Todd PK. FMR1 disorders. In: Adam MP, Ardinger HH, Pagon RA, et al., eds. GeneReviews ${ }^{\circledR}$. University of Washington, Seattle; 1998.

32. Kaufmann WE, Kidd SA, Andrews HF, et al Autism Spectrum disorder in fragile X Syndrome: cooccurring conditions and current treatment. Pediatrics. 2017;139(suppl 3):S194-S206.
33. Kang KW, Kim W, Cho YW, et al Genetic characteristics of non-familial epilepsy. PeerJ. 2019;7:e8278.

34. Hedley PL, Jørgensen P, Schlamowitz S, et al The genetic basis of long QT and short QT syndromes: a mutation update. Hum Mutat. 2009;30(11):1486-1511.

35. SoRelle JA, Thodeson DM, Arnold S, Gotway G, Park JY. Clinical utility of reinterpreting previously reported genomic epilepsy test results for pediatric patients. JAMA Pediatr. 2019;173(1):e182302.

36. Dunn P, Albury CL, Maksemous N, et al Next generation Sequencing methods for diagnosis of epilepsy Syndromes. Front Genet. 2018;9:20.

37. Scala M, Bianchi A, Bisulli F, et al Advances in genetic testing and optimization of clinical management in children and adults with epilepsy. Expert Rev Neurother. 2020;20(3):251-269.

38. Whittaker RG, Devine HE, Gorman GS, et al Epilepsy in adults with mitochondrial disease: a cohort study. Ann Neurol. 2015;78(6):949-957.

39. Wallace DC, Lott MT, Shoffner JM, Ballinger S. Mitochondrial DNA mutations in epilepsy and neurological disease. Epilepsia. 1994;35(suppl 1):S43-S50. 


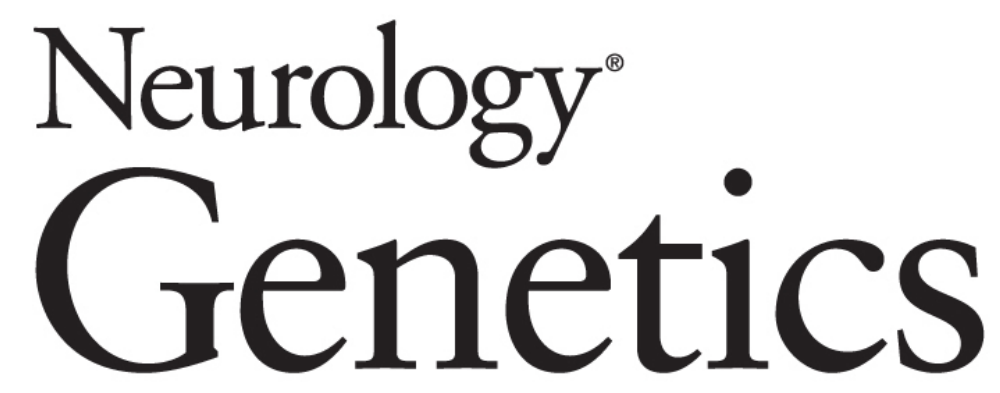

Multigene Panel Testing in a Large Cohort of Adults With Epilepsy: Diagnostic Yield and Clinically Actionable Genetic Findings

Dianalee McKnight, Sara L. Bristow, Rebecca M. Truty, et al.

Neurol Genet 2022;8;

DOI 10.1212/NXG.0000000000000650

This information is current as of December 16, 2021

Neurol Genet is an official journal of the American Academy of Neurology. Published since April 2015, it is an open-access, online-only, continuous publication journal. Copyright Copyright ( 2021 The Author(s).

Published by Wolters Kluwer Health, Inc. on behalf of the American Academy of Neurology.. All rights reserved. Online ISSN: 2376-7839.

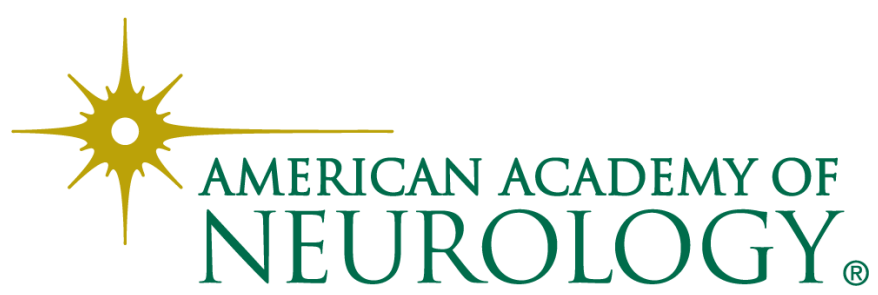




\section{Updated Information \& Services}

\section{References}

Citations

Subspecialty Collections

\section{Errata}

Permissions \& Licensing

\section{Reprints}

including high resolution figures, can be found at: http://ng.neurology.org/content/8/1/e650.full.html

This article cites 34 articles, 0 of which you can access for free at: http://ng.neurology.org/content/8/1/e650.full.html\#\#ref-list-1

This article has been cited by 1 HighWire-hosted articles: http://ng.neurology.org/content/8/1/e650.full.html\#\#otherarticles

This article, along with others on similar topics, appears in the following collection(s):

\section{All Genetics}

http://ng.neurology.org//cgi/collection/all_genetics Antiepileptic drugs

http://ng.neurology.org//cgi/collection/antiepileptic_drugs

An erratum has been published regarding this article. Please see next page or:

/content/8/3/e674.full.pdf

Information about reproducing this article in parts (figures,tables) or in its entirety can be found online at:

http://ng.neurology.org/misc/about.xhtml\#permissions

Information about ordering reprints can be found online: http://ng.neurology.org/misc/addir.xhtml\#reprintsus

Neurol Genet is an official journal of the American Academy of Neurology. Published since April 2015, it is an open-access, online-only, continuous publication journal. Copyright Copyright $\odot 2021$ The Author(s). Published by Wolters Kluwer Health, Inc. on behalf of the American Academy of Neurology.. All rights reserved. Online ISSN: 2376-7839.

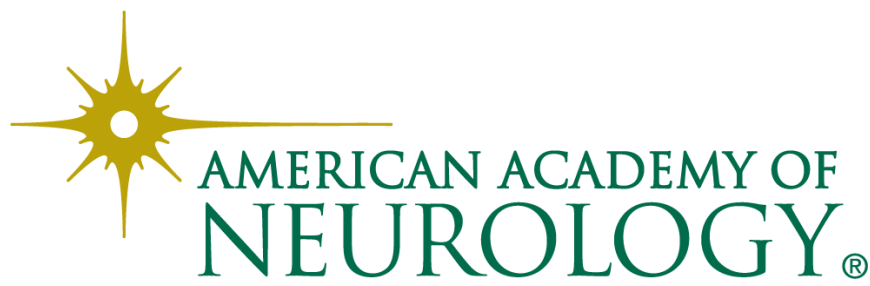




\section{Multigene Panel Testing in a Large Cohort of Adults With Epilepsy}

Diagnostic Yield and Clinically Actionable Genetic Findings

Neurol Genet 2022;8:e674. doi:10.1212/NXG.0000000000000674

In the Article "Multigene Panel Testing in a Large Cohort of Adults With Epilepsy: Diagnostic Yield and Clinically Actionable Genetic Findings" by McKnight et al., ${ }^{1}$ the $y$-axis of Figure 1B should be in increments of 10, starting at 0 and ending at 30 from the bottom up. The updated figure is provided below. The editorial staff regrets the error.

Figure Diagnostic Yield and Genes With Positive Findings

A
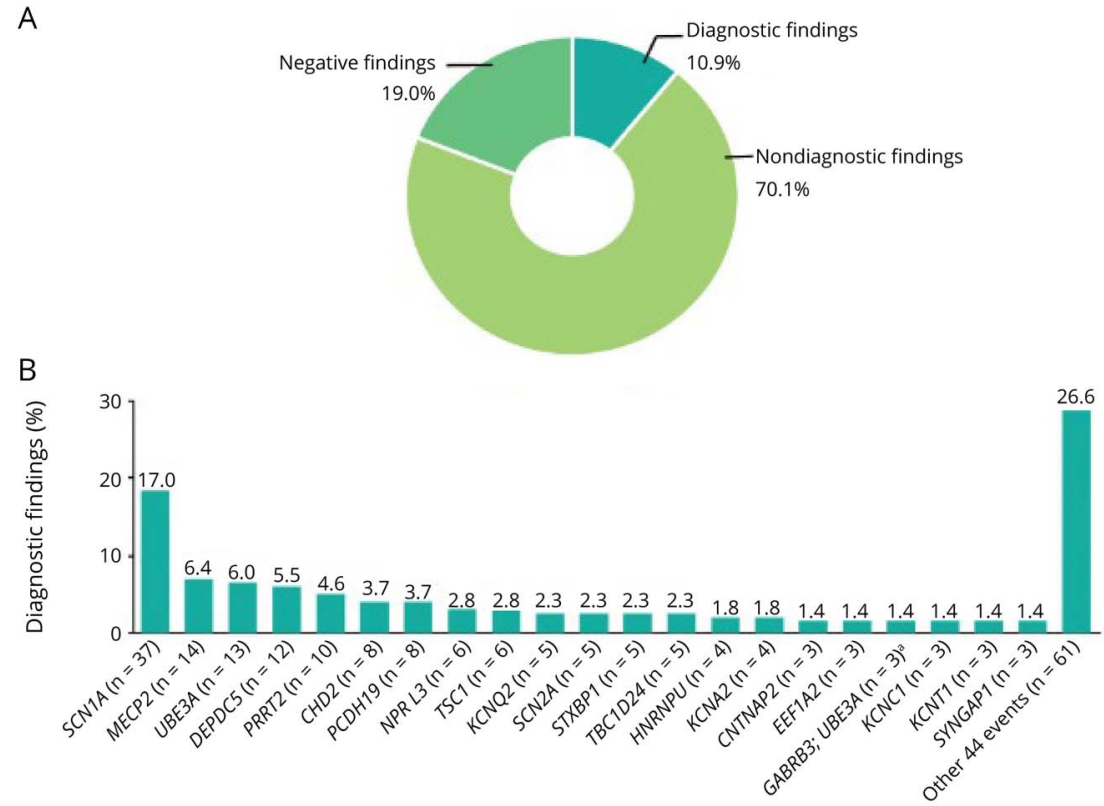

C

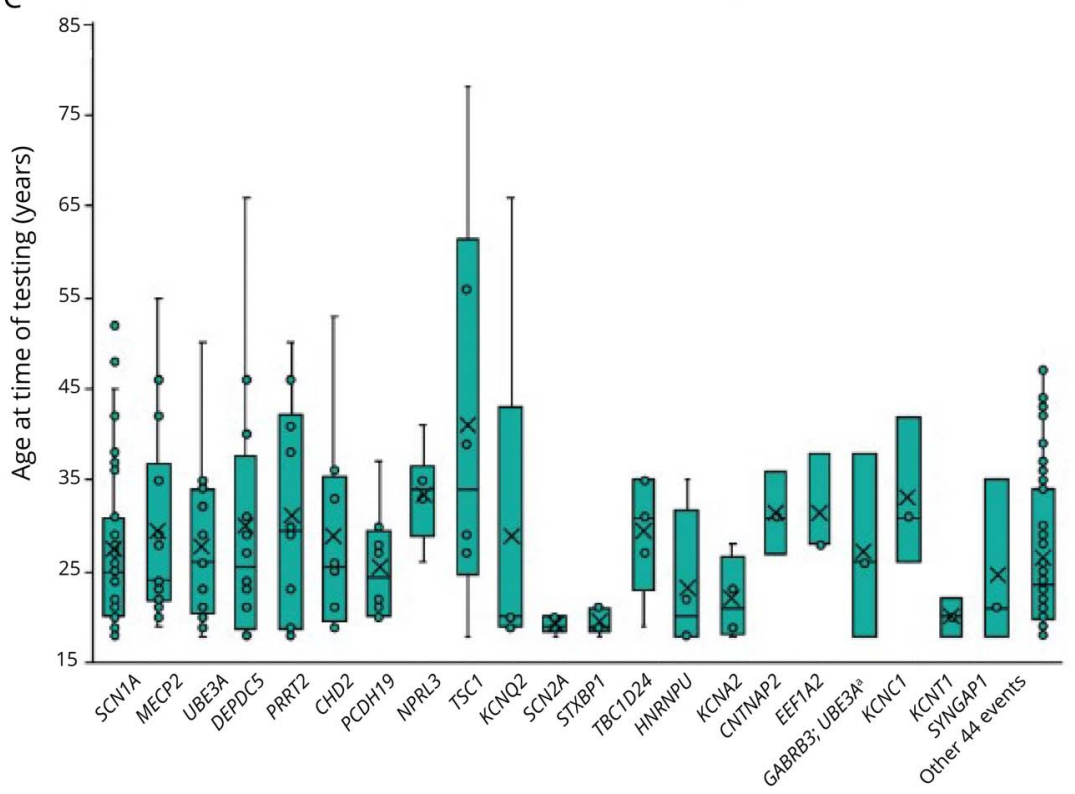

\section{Reference}

1. McKnight D, Bristow SL, Truty RM, et al. Multigene panel testing in a large cohort of adults with epilepsy: diagnostic yield and clinically actionable genetic findings. Neurol Genet. 2022;8(1):e650. 